\title{
Detection of tuberculosis hotspots using spatial interpolation method in Mysuru district, Karnataka
}

\author{
Rakshitha N Rani, Talluri K R Rameshwari, Sumana Kumar* \\ Department of Microbiology, Faculty of Life Sciences, JSS Academy of Higher Education and Research, Mysuru, Karnataka, India.
}

ARTICLE INFO

Article history:

Received on: October 01, 2020

Accepted on: December 05, 2020

Available online: March 10, 2021

\section{Key words:}

Tuberculosis,

Incidence,

Geospatial interpolation method,

Inverse distance weighted,

Hotspots.

\begin{abstract}
Identification of tuberculosis (TB) affected sectors always keeps a check over the transmission in urban regions. Despite adequate therapy, the rate of infection is constant for decades in these regions. Information in residential address and identified TB affected sectors need accordance as per the studies by the researchers. In particular, as an intervention method, geographic information system (GIS) tools on TB epidemiology reveal significant geographical heterogeneity of TB spread in the region. The heterogeneous TB patterns in the local region is due to the person to person disease spread. Due to ongoing person-to-person transmission, TB represents heterogeneous spatial patterns with the local aggregation of cases. Many studies on the combination of TB patients based on their residential address and TB infection sites lack accordance. This study aimed to identify TB incidence using the geospatial features in the reported cases of Mysuru district, in Karnataka. The TB spatial epidemiology in Mysuru district was aimed in a defined geographical area which was deciphered by application of GIS (ArcGIS 10.2.2 demo version) with inverse distance weighted interpolation technique. Based on the reported cases, hotspots reveal, the uneven distribution of TB cases was noticed in Mysuru district. Incidence based spatial analysis suggested possible TB transmission sites and its dynamics in urban areas of Mysuru. Implementing these strategies could be useful for detecting the distribution of TB that can be targeted for screening and initiating the treatment regimen which interrupts the transmission and reduces TB incidence.
\end{abstract}

\section{INTRODUCTION}

One of the air-borne respiratory infection, tuberculosis (TB) caused by Mycobacterium tuberculosis is still a leading cause of morbidity and mortality worldwide over the decades. After the discovery of the infectious nature of the disease discovered by Koch in 1882, the profound knowledge about the pathophysiology and preventive strategies were extensively studied. Unfortunately, TB remains one among the global public health problem, standing $10^{\text {th }}$ in an order with subsequent disease related to heart and stroke, etc.

In 1993, the World Health Organization (WHO) declared TB as a global health emergency [1,2]. Later in 2015, the WHO launched a surveillance program for TB and for past two decades, the program was considered as a sustainable accomplishment. Where, 58 million lives saved from 2000 to 2018 through diagnosis and treatment with notified cases (1.0 million cases in 2000 and 7.0 million in 2018).

Geographically, recorded TB cases in 2018 were detected in the WHO regions, namely, South-East Asia (44\%), Africa (24\%), Western Pacific

*Corresponding Author:

Sumana Kumar, Department of Microbiology,

Faculty of Life Sciences, JSS Academy of Higher

Education and Research, Mysuru - 570015, Karnataka, India.

E-mail: sumana.k@jssuni.edu.in
(18\%), Eastern Mediterranean (8\%), America (3\%), and Europe (3\%). Two third of the cases accounted in South East Asian countries, namely, India (27\%), China (9\%), Indonesia (8\%), Philippines (6\%), Pakistan (6\%), Nigeria (4\%), Bangladesh (4\%), and South Africa (3\%) (WHO report 2019).

However, in 2018 estimated 10 million cases were detected, out of which 5.7 million and 3.2 million were men and women, respectively. In 2018, India accounted for 2.69 million cases, out of which 13 lakh and 7 lakh TB cases were among men and women, respectively. According to the records, India accounts along with eight other countries, accounted for $66 \%$ new cases in 2018 alone with 1.5 million TB mortality [3]. Karnataka accounted for a total of 83,094 positive cases, with 54,924 and 28,101 TB cases among male and female, respectively [4]. The reported cases of TB in Mysuru urban region found to be highest amongst all and among certain high-risk areas. All these aspects can be targeted to identify the current TB status in Mysuru district that pose the risk of spreading the infectious agent.

New technologies in molecular epidemiological methods developed reveal the mode of TB transmission [5-7]. However, the application of geographic information system (GIS) in the field of epidemiology has the trend in analyzing TB incidence with the available geographical data which describes the visualization and TB spatial distribution. The combination of the spatial distribution for the epidemiological

(C) 2021 Rani, et al. This is an open access article distributed under the terms of the Creative Commons Attribution License -NonCommercial-ShareAlike Unported License (http://creativecommons.org/licenses/by-nc-sa/3.0/). 
studies like three dimensional analysis using inverse distance weighted (IDW) was used to understand the transmission of TB at the WorthDallas metropolitan area of U.S., SaTScan ${ }^{\mathrm{TM}}$ v4.0.311 to analyze spatial relationships in Island of Montreal, Canada, and Spatial TB distribution study at Baltimore has been applied in the current study to understand the TB transmission $[6,8,9]$.

In the current study, incidence of pulmonary TB cases in Mysore district was investigated using Arc GIS 10.2.2 (demo version) with a tool IDW. The present objectives of our study were to determine an epidemiological survey of spatial patterns of pulmonary TB cases in the Mysuru district.

\section{MATERIALS AND METHODS}

\subsection{The Study Area}

Mysuru city $\left(155.7 \mathrm{~km}^{2}\right)$ is one of the southern parts of the Karnataka state province in India and Headquarter of Mysuru Administrative District [10]. The city covers the diverse urban areas and rural environment with residential, commercial, and industrial zones. The Mysuru district covers an estimated population of 1.7 million in 2019. Climate of the area has a moderate type $17-37^{\circ} \mathrm{C}$; thus, agriculture, industries, and information technology are the mainstay of the people [11].

\subsubsection{Data collection}

The study detects the incidence of TB annually from 2011 to 2018, assessing incidence cases reported by National Tuberculosis Elimination Program (previously called Revised National Tuberculosis Control Program [RNTCP]). It is a retrospective analysis of the incidence of TB at Mysuru district of Karnataka. The cases of pulmonary TB in rural and urban areas were estimated by the RNTCP survey from 2011 to 2018, which served for the detection of spatial patterns of TB in Mysuru district by GIS tool.

\subsection{Methods}

The collected TB data were evaluated by the IDW which is one among three key interpolation methods for the cluster detection, namely, local polynomial and IDW (deterministic methods) and kernel smoothing which are three key spatial autocorrelation indices used to detect spatial aggregation of TB by creating TB patient density surface by nearby TB cases around the interpolated point were identified and a weighted average is considered in the spotted region within the neighborhood resulting in hotspots and cold spots in map $[12,13]$.

The spatial anomalies in hotspot regions were studied using global Moran's index (Moran's I) and local Getis-Ord (Gi*) statistics that describe spatial clusters and areas in which these are situated. The values range from -1 to +1 indicates perfect dispersion to perfect correlation. Expected value of Moran's I under null hypothesis of no spatial autocorrelation with negative value indicates negative spatial autocorrelation. The value range from -1 indicates the perfect dispersion to +1 perfect correlation. Each hotspots analysis calculates the Getis-Ord Gi* static in a dataset. The analysis results in z-score and $P$-values reveal the spatial cluster of characteristics with either high or low values. The tool analyzes each feature within the context of neighboring features.

The spatial autocorrelation tool based on the moran's index, Expected Index, Variance, $\mathrm{z}$-score, and $P$-value. It assesses whether the pattern represented is clustered, scattered, or random, given a set of features and an associated attribute. To determine the importance of that index, the tool calculates the Moran's I Index value and both a z-score and a $P$-value. $P$-values for a specified distribution are numerical approximations of the area under the curve with limited statistics. Under the null hypothesis expected value of Moran's I with no spatial autocorrelation that is negative values indicates negative spatial autocorrelation and positive inverse values. The value range from -1 indicates the perfect dispersion to +1 perfect correlation. The $\mathrm{Gi}^{*}$ statistics returned for each feature in a dataset is a z-score. The larger the $\mathrm{z}$-score, more intense the clustering of hotspots (high values), and smaller the z-scores, more intense the clustering of cold spots (low values). The subsequent analysis of these data was assessed in IDW an interpolation method to understand the TB patterns. However, the selection of the interpolation method was based on the validation criteria to identify the most accurate method [14].

\subsection{GIS Mapping}

The TB patterns analysis created by mapping the disease prospects at urban region of the Mysuru district was determined by generating the proportion at the highly reported area over the average incidence from 2011 to 2018 . Disease possibility was estimated by the average incidence of all areas with the ratio of the observed incidence [15]. To estimate disease possibility, the average incidence of all areas with the ratio of the observed incidence was calculated. The TB cases in India were spotted by Getis-Ord with computer tomography which detects the hotspots and cold spots. The collected data were surveyed and mapped using ArcGis (10.2.2 demo version).

\section{RESULTS}

The distribution of reported PTB cases in Mysuru district from 2011 to 2018 was investigated using GIS software. The demographic data of the patient's information include age, gender, and locality selected for the study. The total reported cases from 2011 to 2018 reveals 14,146 PTB patients in Mysuru district with 10,308 (81\%) and 3838 (30\%) men and women, respectively. In addition, Mysuru urban region found to be the highest reported PTB patients with 5172 (41\%) cases from 2011 to 2018. On geocoding (total PTB), cases of PTB infected people in a three dimensional analysis method IDW hotspots of the area with high infection rate was determined. To study the intensity of the infection from 2011 to 2018, the reported cases of PTB were mapped [Figure 1].

On mapping the reported data, Mysuru urban region found to be the highest in PTB cases. Further, the work was extended to study the infection rate among men [Figure 2] and women [Figure 3] in the region.

As illustrated in the map, the PTB infected area varied from 2011 to 2018. Evaluation of TB dispersion in Mysuru district with GIS revealed a geographical heterogeneity that is uneven distribution with various concentration of TB in the Mysuru district.

All province of the district was found to increase in TB infection with population increase. The Mysuru urban population was found to be higher with increase population and PTB cases [Table 1].

The population density of Mysuru district is the second largest that around 14, 56, 651 and 18, 28, 096 in urban and rural regions, respectively. The prevalence of TB patients is seen to be higher in the Mysuru Urban city [Figure 2]. Most of the health care centers are located in Mysuru urban city. The district has the largest and wider geographical region, the distribution of patient number was found higher than that of the other talukas. The talukas with less urbanization and high access to nature have less patient's dispersion statistics. The result revealed most TB patients which were distributed in Mysuru 


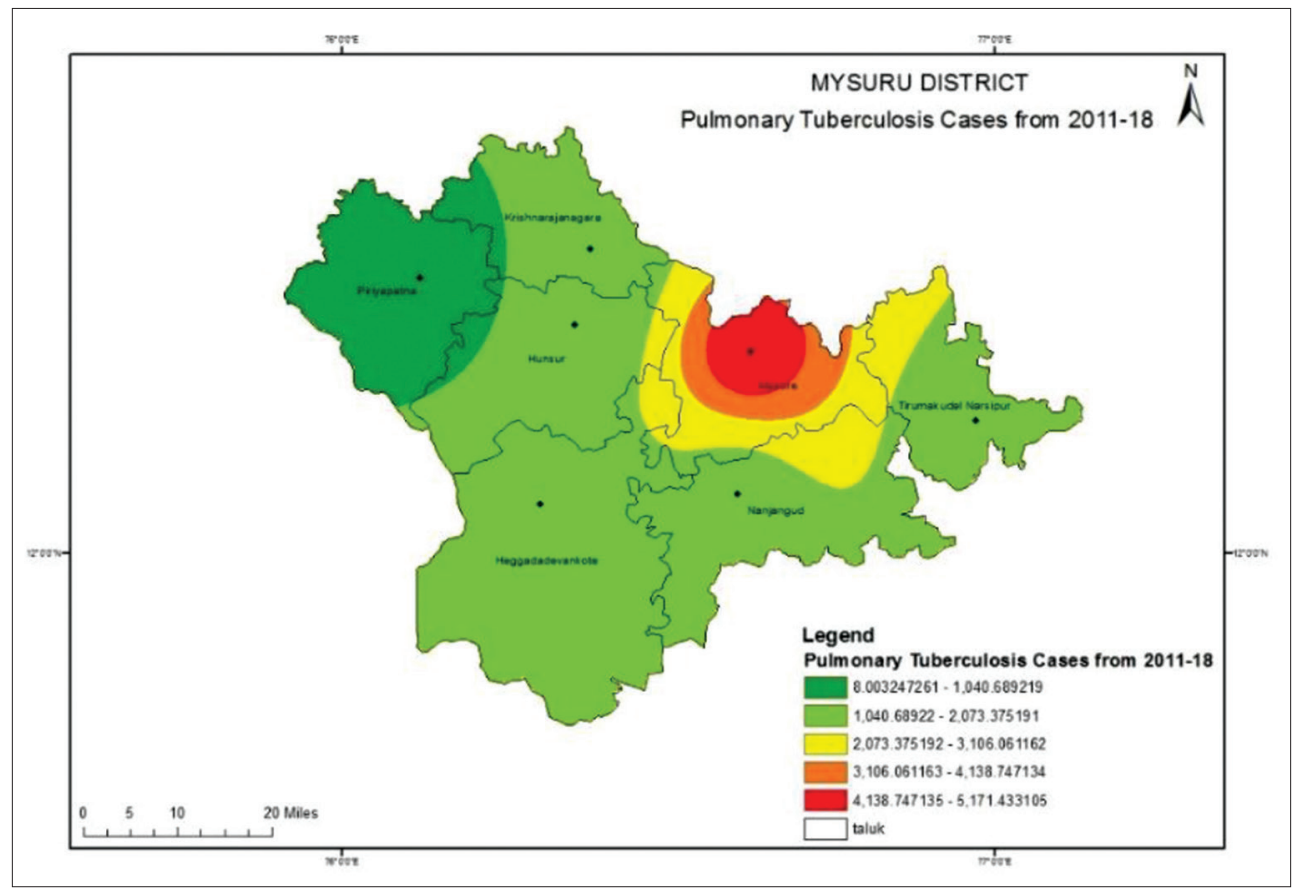

Figure 1: Total pulmonary tuberculosis cases in Mysuru district (2011-2018).

Table 1: Pulmonary tuberculosis cases with population in Mysuru district 2011-2018.

\begin{tabular}{ccc} 
Year & Population & Pulmonary \\
2011 & $2,994,744$ & 1,473 \\
2012 & $3,033,861$ & 1,527 \\
2013 & $3,073,719$ & 1,493 \\
2014 & $3,114,339$ & 1,381 \\
2015 & $3,155,734$ & 1,389 \\
2016 & $3,197,920$ & 1,315 \\
2017 & $3,240,918$ & 3,095 \\
2018 & $3,284,747$ & 2,544 \\
\hline
\end{tabular}

district located in the southern part of Karnataka that has high socioeconomic status.

Indeed there were only a total of 592 and 1173 positive PTB cases reported in talukas of Mysuru District, namely, Periyapatna and Krishnarajanagara (KR Nagar), respectively, from 2011 to 2018. Highest reported cases were 5172 in Mysuru followed by 1513 cases in Nanjangud from 2011 to 2018. On comparing the population density in this region, Periyapatna and KR Nagar have the least followed by Mysuru and Nanjangud with the highest population.

The total cases detected in men and women were 10,308 and 3,838 (2011-2018), respectively. As a result, the percentage of men is almost twice that of women. This ratio was observed in most of the talukas of the Mysuru urban as well as all districts of Mysuru [Figure 3a and b].

In this contrast, the overcrowding factors seem to have a prominent role in TB dispersion. In fact, urban city has favorable access to public health centers and resources with an increased number of positive cases in the respective year of 451 (2011), 479 (2012), 490 (2013), 428 (2014), 452 (2015), 553 (2016), 1099 (2017), and 1220 (2018). Yet, overcrowding in this residential region may cause a drastic increase of PTB [Figure 2]. Mysuru urban region poses high vulnerability and burden zones among all the talukas of Mysuru district.

\section{DISCUSSION}

A study on TB transmission at Rio de Janeiro, Brazil, demonstrated a community-wide transmission that is likely to occur in small, geographically defined hotspots containing $6 \%$ of city's population, $16.5 \%$ of $\mathrm{TB}$ incidence, and $35.3 \%$ of ongoing $\mathrm{TB}$ transmission events [16]. Few studies in health care providers and patients with chest symptoms during population-based surveys were obtained the representative data in high-burden states [17]. Many of these associations align with other research that has also been shown to be higher in lower racial/ethnic groups in Brazil's TB incidence [18-20], more crowded household [21-26] and in high populated areas [27-29]. Age and gender have been observed as strong determinants of TB disease, with a higher risk of TB disease amongst geriatrics and in males with possibilities like low activity of the immune system and exterior work, respectively [30]. Four previous TB prevalence surveys conducted in the neighboring Tiruvallur district and numerous other studies conducted in India and other parts of the world have made similar observations [31-33]. In addition, a survey also showed a very high prevalence of PTB disease among men above 55 years of age [34].

Our findings confirm that TB to consider a major public health problem in this southern Indian city and highlights the need for rethinking current TB control strategies. Future research should study the impact of interventions, including deployment of more sensitive diagnostics in certain areas, active case finding in high-risk groups, engaging private practitioners in TB control by usage of mask in highrisk groups, and also by undertaking an extensive media campaign. The city has been exposed to urbanization and industrial areas which also include less agricultural and mountain regions. Therefore, a significant relationship between regional development and the TB distribution can be observed. 


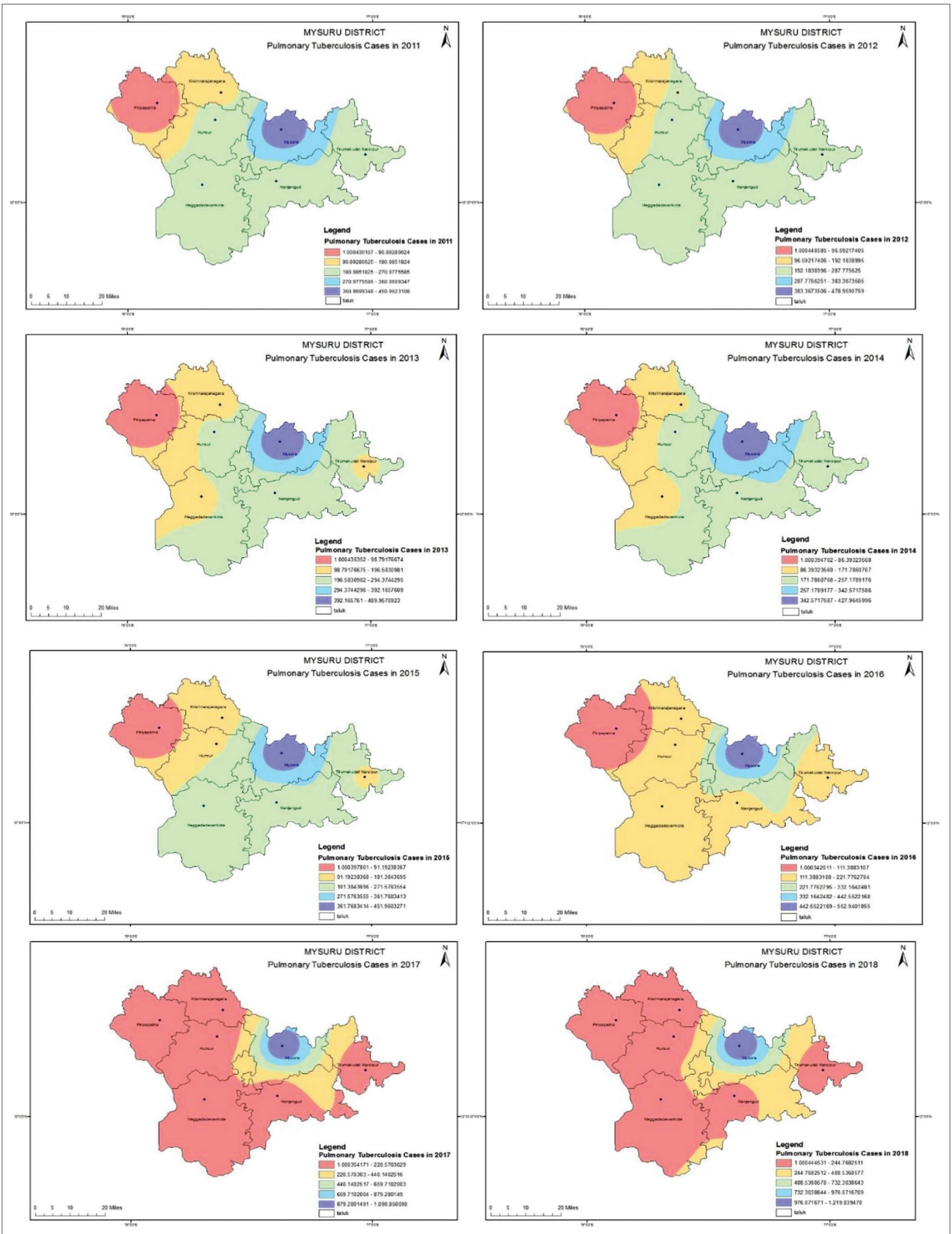

Figure 2: Year-wise pulmonary tuberculosis cases in Mysuru district (2011-2018). 


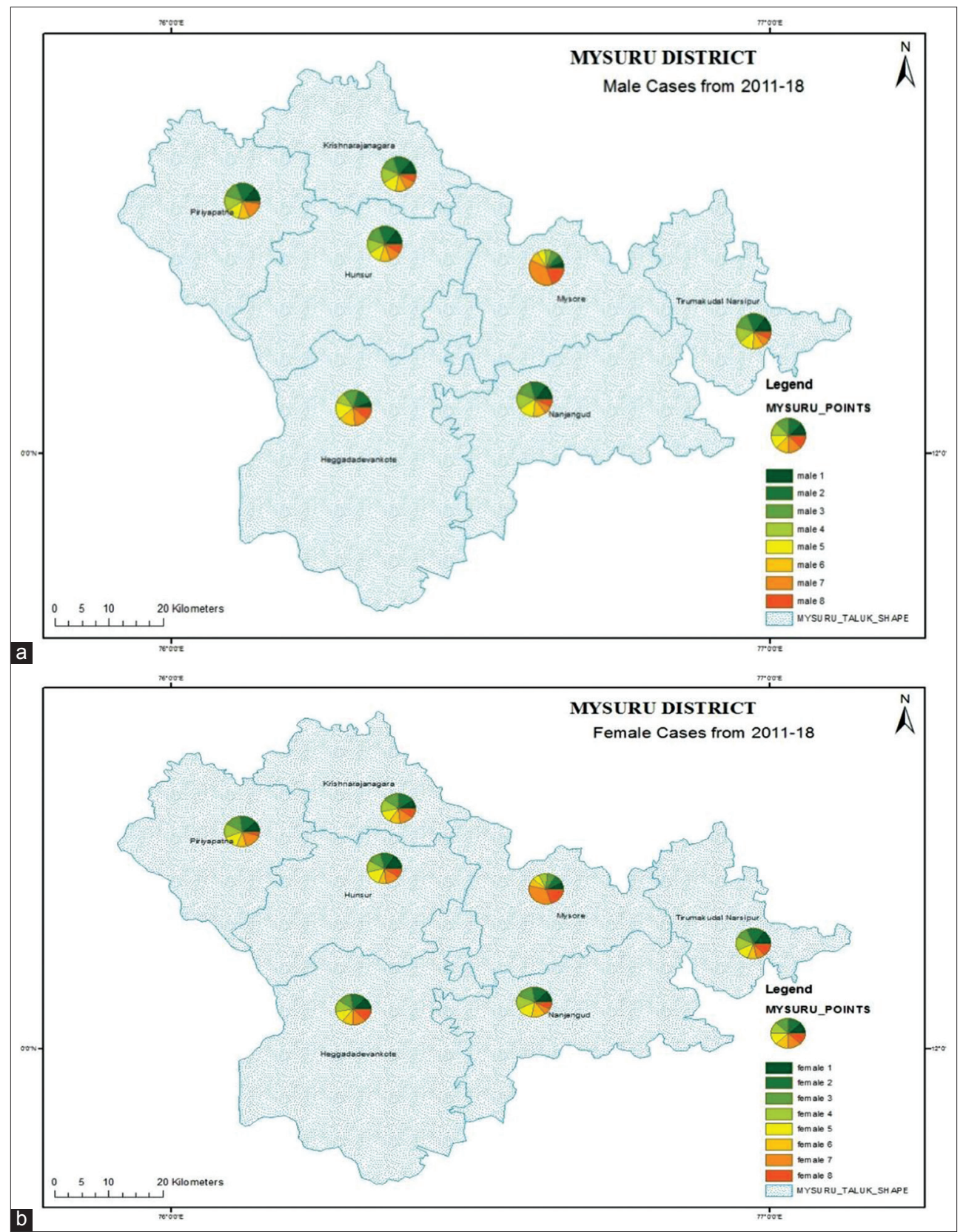

Figure 3: (a) The total reported cases of pulmonary tuberculosis in men from 2011 to 2018 (b) The total reported cases of pulmonary tuberculosis in women from 2011 to 2018.

\section{CONCLUSION}

Evaluation of PTB hotspots in Mysuru district with GIS revealed a geographical heterogeneity which can be used as one of the epidemiological tools in the health care sectors that can be able to access TB incidence, current scenario, and prediction on TB transmission in the area. In addition, these results could be useful to develop guidelines for more directed TB control strategies in specific geographical areas with high PTB prevalence. Considering the results of this study, urban and rural areas, which have been considered as high populated areas around Mysuru district that may be represented as a high prevalence of PTB. The study showed that the non-random spatial distribution of PTB in the district of Mysuru was clustered with important spatial patterns for high incidence. In addition, TB patterns in men found to be twice that of the women that may be account to the lifestyle adopted.
Indeed, numerous studies have been reported the significant role of socioeconomic conditions, including hygienic conditions and overcrowding in specific geographical regions [35]. To minimize the high burden and variation of the outbreak of the disease, the abovementioned factors should be taken into account by the health care authorities around the world. The data definitely would help healthcare authorities to make better decisions about developing new strategies to handle TB transmission in the studied area and direct the interventions to sites where they are most needed. The results obtained illustrate that the GIS could serve as a link between biomedical and social sciences. It will become possible to identify and map medically vulnerable populations and various risk factors and their combinations and to correlate these findings with treatment region the knowledge over and epidemiological trends over time. The capacity of GIS to link 
the disease information with environmental and spatial data makes it an effective tool for TB prevention worldwide. Thus, it is possible to conduct geographically based screening and use the results to develop improved programs for controlling TB based on the obtained evidence.

\section{ACKNOWLEDGMENT}

The authors would like to thank Division of Geo-informatics, Department of Water and Health, Faculty of Life Sciences, JSSAHER for their help with generating map.

\section{AUTHOR CONTRIBUTIONS}

All authors made substantial contributions to conception and design, acquisition of data, or analysis and interpretation of data; took part in drafting the article or revising it critically for important intellectual content; agreed to submit to the current journal; gave final approval of the version to be published; and agree to be accountable for all aspects of the work. All the authors are eligible to be an author as per the international committee of medical journal editors (ICMJE) requirements/guidelines.

\section{FUNDING}

There is no funding to report.

\section{CONFLICTS OF INTEREST}

The authors report no financial or any other conflicts of interest in this work.

\section{ETHICAL APPROVALS}

Not applicable.

\section{PUBLISHER'S NOTE}

This journal remains neutral with regard to jurisdictional claims in published institutional affiliation.

\section{REFERENCES}

1. Daniel TM. The history of tuberculosis. Respir Med 2006;100:1862-70.

2. Raviglione MC, Snider DE, Kochi A. Global epidemiology of tuberculosis. Morbidity and mortality of a worldwide epidemic. JAMA 1995;273:220-6.

3. Available from: https://www.who.int/tb/publications/factsheet_ global.pdf. [Last accessed on 2019 Jul 11].

4. Available from: https://bcindia.gov.in/index1. php?lang $=1 \&$ level $=1 \&$ sublinkid $=4160 \&$ lid $=2807$. [Last accessed on 2019 Nov 11].

5. Anderson LF, Tamne S, Brown T, Watson JP, Mullarkey C, Zenner D, et al. Transmission of multidrug-resistant tuberculosis in the UK: A cross-sectional molecular and epidemiological study of clustering and contact tracing. Lancet Infect Dis 2014;14:406-15.

6. Bishai WR, Graham NM, Harrington S, Pope DS, Hooper N, Astemborski J, et al. Molecular and geographic patterns of tuberculosis transmission after 15 years of directly observed therapy. JAMA 1998;280:1679-84.

7. Murray M, Nardell E. Molecular epidemiology of tuberculosis: Achievements and challenges to current knowledge. Bull World Health Organ 2002;80:477-82.

8. Haase I, Olson S, Behr MA, Wanyeki I, Thibert L, Scott A, et al. Use of geographic and genotyping tools to characterise tuberculosis transmission in Montreal. Int J Tuberc Lung Dis 2007;11:632-8.

9. Moonan PK, Bayona M, Quitugua TN, Oppong J, Dunbar D, Jost KC Jr., et al. Using GIS technology to identify areas of tuberculosis transmission and incidence. Int $\mathrm{J}$ Health Geogr 2004;3:23

10. Myuru District website, Mysuru City Corporation. Available from: https://www.mysore.nic.in/en/public-utility/mysuru-citycorporation. [Last accessed on 2019 Apr 20].

11. Ningaraju D, Das SA. Cropping pattern and crop ranking of Mysore district. Int J Res 2017;5:334-38.

12. Lloyd CD. Local Models for Spatial Analysis. $2^{\text {nd }}$ ed. United States: CRC Press; 2010.

13. Izumi K, Ohkado A, Uchimura K, Murase Y, Tatsumi Y, Kayebeta A, et al. Detection of tuberculosis infection hotspots using activity spaces based spatial approach in an Urban Tokyo, from 2003 to 2011. PLoS One 2015;10:e0138831.

14. Ibrahim S, Hamisu I, Lawal U. Spatial pattern of tuberculosis prevalence in Nigeria: A comparative analysis of spatial autocorrelation indices. Am J Geogr Inform Sys 2015;4:87-94.

15. Kakchapati S, Choonpradub C, Lim A. Spatial and temporal variations in tuberculosis incidence, Nepal. Southeast Asian J Trop Med Public Health 2014;45:95.

16. Dowdy DW, Golub JE, Chaisson RE, Saraceni V. Heterogeneity in tuberculosis transmission and the role of geographic hotspots in propagating epidemics. Proc Natl Acad Sci U S A 2012;109:9557.

17. Sreeramareddy CT, Qin ZZ, Satyanarayana S, Subbaraman R, Pai M. Delays in diagnosis and treatment of pulmonary tuberculosis in India: A systematic review. Int J Tuberc Lung Dis 2014;18:255-66.

18. Coimbra CE, Basta PC. The burden of tuberculosis in indigenous peoples in Amazonia, Brazil. R Soc Trop Med Hyg 2007;101:635-6.

19. Hoeppner VH, Marciniuk DD. Tuberculosis in aboriginal Canadians. Can Respir J 2000;7:141-6.

20. Miramontes R, Hill AN, Woodruff RS, Lambert LA, Navin TR, Castro KG, et al. Tuberculosis infection in the United States: Prevalence estimates from the national health and nutrition examination survey, 2011-2012. PLoS One 2015;10:e140881.

21. Baker M, Das D, Venugopal K, Howden-Chapman P. Tuberculosis associated with household crowding in a developed country. J Epidemiol Community Health 2008;62:715-21.

22. Cantwell MF, Mckenna MT, Mccray E, Onorato IM. Tuberculosis and race/ethnicity in the United States: Impact of socioeconomic status. Am J Respir Crit Care Med 1998;157:1016-20.

23. Corbett EL, Bandason T, Cheung YB, Makamure B, Dauya E, Munyati SS, et al. Prevalent infectious tuberculosis in Harare, Zimbabwe: Burden, risk factors and implications for control. Int $\mathbf{J}$ Tuberc Lung Dis 2009;13:1231-7.

24. Munch Z, Van Lill SW, Booysen CN, Zietsman HL, Enarson DA, Beyers N. Tuberculosis transmission patterns in a high incidence area: A spatial analysis. Int J Tuberc Lung Dis 2003;7:271-7.

25. Murry M, Oxlade O, Lin HH. Modeling social, environment and biological determinants of tuberculosis patterns in a high-incidence area: A spatial analysis. Int J Tuberc Lung Dis 2011;7:271-7.

26. Souza WV, Carvalho MS, Albuquerque MF, Lapa TM, Portugal JL, Lima ML, et al. The use of socioeconomic factors in mapping tuberculosis risk areas in a city of Northeastern Brazil. Rev Panam Salud Publica 2000;8:403-10.

27. Goncalves MJ, Leon AC, Penna ML. A multi-level analysis of tuberculosis associated factors. Rev Salud Publica 2009;11:918-30.

28. Liu Y, Li X, Wang W, Li Z, Hou M, He Y, et al. Investigation of space-time clusters and geospatial not spots for the occurrence of tuberculosis in Beijing. Int J Tuberc Lung Dis 2012;16:486-91.

29. Tanrikulu AC, Acemoglu H, Palanci Y, Dagli CE. Tuberculosis in Turkey: High altitude and other socio-economic risk factors. Public Health 2008;122:613-9. 
30. Lönnroth K, Castro KG, Chakaya JM, Chauhan LS, Floyd K, Glaziou P, et al. Tuberculosis control and elimination 2010-50: Cure, care, and social development. Lancet 2010;375:1814-29.

31. Gopi PG, Subramani R, Radhakrishna S, Kolappan C, Sadacharam K, Devi TS, et al. A baseline survey of the prevalence of tuberculosis in a community in South India at the commencement of a DOTS programme. Int J Tuberc Lung Dis 2003;7:1154-62.

32. Hoa NB, Tiemersma EW, Sy DN, Nhung NV, Vree M, Borgdorff MW, et al. Health-seeking behaviour among adults with prolonged cough in Vietnam. Trop Med Int Health 2011;16:1260-7.

33. Kolappan C, Gopi PG, Subramani R, Narayanan PR. Selected biological and behavioural risk factors associated with pulmonary tuberculosis. Int J Tuberc Lung Dis 2007;11:999-1003.
34. Dhanaraj B, Papanna MK, Adinarayanan S, Vedachalam C, Sundaram V, Shanmugam S, et al. Prevalence and risk factors for adult pulmonary tuberculosis in a metropolitan city of South India. PLoS One 2015;10:e0124260.

35. McConkey SJ, Williams M, Weiss D, Adams H, Cave MD, Yang Z, et al. Prospective use of molecular typing of Mycobacterium tuberculosis by use of restriction fragment-length polymorphism in a public tuberculosis-control program. Clin Infect Dis 2002;34:612-9.

\section{How to cite this article:}

Rani RN, Rameshwari TKR, Kumar S. Detection of tuberculosis hotspots

using spatial interpolation method in Mysuru district, Karnataka. J App Biol

Biotech. 2021;9(2):124-130. DOI: 10.7324/JABB.2021.9211 